\title{
Nicorandil Infusion Leads to Good Recovery From Ischemia of Left Ventricular Regional Work in Comparison With Nitroglycerin
}

\author{
Naoki Isobe, MD; Shigeru Oshima, MD; Koichi Taniguchi, MD; Hiroshi Hoshizaki, MD; \\ Hitoshi Adachi, MD; Takuji Toyama, MD; Shigeto Naito, MD; \\ Akihiko Nogami, MD; Motoaki Sugawara, PhD*
}

\begin{abstract}
Nicorandil is an antianginal drug that exerts both a conventional nitrate effect and an independent ATP-dependent potassium channel-opening effect. The present study examined the effects of nicorandil on left ventricular regional work (RW) during coronary angioplasty in 22 patients with angina pectoris who were scheduled for angioplasty to the left anterior descending artery. The patients were randomly assigned to receive either nitroglycerin (group NG, $\mathrm{n}=12,0.5 \mu \mathrm{g} \cdot \mathrm{kg}^{-1} \cdot \mathrm{min}^{-1}$ ) or nicorandil (group NR, $\mathrm{n}=10,1.5 \mu \mathrm{g} \cdot \mathrm{kg}^{-1} \cdot \mathrm{min}^{-1}$ ). Inflation was performed for $60 \mathrm{~s}$ and the data were collected every $10 \mathrm{~s}$. The RW was derived from the relation between mean wall stress and area strain. The RW of the interventricular septum decreased after balloon inflation and was at its minimum after the $60 \mathrm{~s}$ inflation (group NR: $1.24 \pm 0.72 \mathrm{~mJ} / \mathrm{cm}^{3}$, group NG: $0.63 \pm 0.25 \mathrm{~mJ} / \mathrm{cm}^{3}$ ). After balloon deflation, the septal RW of both groups increased, and recovered to the baseline condition at about $30 \mathrm{~s}$. At $20 \mathrm{~s}$ after deflation, the septal RW in group NR $\left(3.58 \pm 1.17 \mathrm{~mJ} / \mathrm{cm}^{3}\right)$ was significantly higher than that in group NG $\left(2.25 \pm 0.59 \mathrm{~mJ} / \mathrm{cm}^{3}\right)(\mathrm{p}<0.05)$. An intravenous infusion of nicorandil led to good recovery of RW from ischemia compared with that obtained with nitroglycerin. (Circ J 2002; 66: 943-948)
\end{abstract}

Key Words: Ischemia; Left ventricle; Nicorandil; Percutaneous transluminal coronary angioplasty; Recovery; Regional work; Stress/strain relation

$\mathbf{N}$ icorandil (NR), a nicotinamide-nitrate ester [N-(2hydroxyethyl)-nicotinamide nitrate)], is an antianginal drug with 2 characteristic functions: the conventional nitrate effect mediated by cyclic guanosine monophosphate (cGMP), and an independent ATP-dependent potassium channel-opening effect - $^{-5}$ Nitrates induce arterial and venous dilatation of the epicardial coronary vessels, including the stenotic segment, by increasing cGMP within the vascular smooth muscle cells. ${ }^{6-9}$ The potassium-channel opening effect is believed to reduce calcium influx secondary to action potential shortening and thus prevent or attenuate membrane depolarization, which in turn may lead to reduced ATP consumption during ischemia ${ }^{10}$ The unique cardioprotective function of NR suggests that it may have advantages over other available antianginal agents.

Percutaneous transluminal coronary angioplasty (PTCA) is an important interventional therapy widely used to treat patients with coronary artery disease. The myocardial conditions induced by the PTCA procedure are an ideal human model of transient myocardial ischemia that provides an appropriate opportunity to study the effect of antianginal agents.

Sugawara et al have proposed a relationship between

(Received November 6, 2001; revised manuscript received July 8, 2002; accepted July 23, 2002)

Division of Cardiology, Gunma Prefectural Cardiovascular Center, Maebashi, Gunma and *Department of Cardiovascular Sciences, Tokyo Women's Medical University, Tokyo, Japan

Mailing address: Naoki Isobe, MD, Division of Cardiology, Gunma Prefectural Cardiovascular Center, 3-12 Kameizumi-machi, Maebashi, Gunma 371-0004, Japan. E-mail: isobe.n@cvc.pref.gunma.jp mean wall stress and strain (the natural logarithm of the reciprocal of wall thickness) to analyze ventricular regional work (RW) ${ }^{11-18}$ and their concept has been applied in clinical studies ${ }^{19-23}$ We used their concept to assess changes in left ventricular (LV) RW during PTCA, and compared the effects of NR and nitroglycerin (NG) on the recovery of RW from ischemia.

Methods
Patients
Twenty-two patients (15 men, 7 women; age (mean \pm SD),
$63 \pm 8$ years) with stable angina pectoris were recruited. The
frequency of chest pain was less than twice per week. They
were scheduled for PTCA to a significant stenosis in the
proximal left anterior descending artery (LAD). All patients
had single-vessel coronary artery disease without angio-
graphic evidence of collateral circulation and with normal
wall motion assessed by both 2-dimensional (D) echocar-
diography and left ventriculography. Patients with unstable
angina, recent or previous myocardial infarction, arrhythmia
(atrial fibrillation etc), valvular diseases, or other cardiac
disease were excluded. Moreover, patients with systemic
disease (hypertension, diabetes mellitus etc), which would
influence cardiac function, were also excluded. All patients
underwent exercise $201 \mathrm{Tl}$ myocardial scintigraphy, which
confirmed that they had myocardial ischemia in the LAD
region. No patients received $\beta$-adrenergic blocking agents,
calcium channel blocking agents, or other cardiovascular
drugs within $48 \mathrm{~h}$ of the study. We explained the content of
the study to all participants and they gave written informed
consent.

Circulation Journal Vol.66, October 2002 
The patients were randomly assigned to receive either NR (group NR; n=10, $7 \mathrm{M}, 3 \mathrm{~F}$; age, 64 7 years) or NG (group NG; $n=12,8 \mathrm{M}, 4 \mathrm{~F}$; age, $62 \pm 8$ years). The LV ejection fraction (LVEF) was $69 \pm 4 \%$ in group NR and $72 \pm 4 \%$ in group NG. The severity of coronary stenosis before PTCA was $84 \pm 7 \%$ in group NR and $82 \pm 7 \%$ in group NG. No statistically significant differences were found between the 2 groups.

\section{Electrocardiography}

A standard 12-lead electrocardiogram (ECG) was monitored and recorded continuously on paper at a speed of $25 \mathrm{~mm} / \mathrm{s}$ before, during and after balloon inflation. Leads $\mathrm{V}_{2}$ and $\mathrm{V}_{3}$ were slightly below their usual location because of the simultaneous recording of echocardiography. Calibration was performed at the beginning of the procedure $(1 \mathrm{mV}=10 \mathrm{~mm})$. ST-segment elevation was measured at $80 \mathrm{~ms}$ after the $\mathrm{J}$ point at the maximum deviation of chest leads.

\section{Angiography}

Coronary angiography and left ventriculography were performed in the usual manner within several days before PTCA. Left ventriculography was performed in the $30^{\circ}$ right anterior oblique view by injecting $30 \mathrm{ml}$ of contrast medium at a rate of $12 \mathrm{ml} / \mathrm{s}$ and the LVEF was calculated using the area-length method. Coronary angiography was performed in multiple views with pre-administration of NG. The severity of stenosis was measured in the following manner. A single angiographic view showing the stenosis at its most severe narrowing was selected and manually traced. Coronary artery diameter was then measured with calipers and a ruler by an observer without knowledge of other study results and then the percent diameter reduction was calculated. The presence or absence of collateral filling of the LAD was assessed from angiograms obtained during contrast injection of the right coronary artery performed before the PTCA procedure. Collaterals were considered absent when diagnostic angiography showed no collateral circulation.

\section{Angioplasty Procedure and Study Protocol}

Six hours before PTCA, a continuous intravenous drip infusion of a low-tension electrolyte solution (Soldem 3A, Terumo, Tokyo, Japan; 150-200 ml/h) was begun, and $4 \mathrm{~h}$ before PTCA, group NR received a continuous intravenous infusion of $\mathrm{NR}\left(1.5 \mu \mathrm{g} \cdot \mathrm{kg}^{-1} \cdot \mathrm{min}^{-1}\right)$ and group $\mathrm{NG}$ received $\mathrm{NG}\left(0.5 \mu \mathrm{g} \cdot \mathrm{kg}^{-1} \cdot \mathrm{min}^{-1}\right)$. An $8 \mathrm{~F}$ guiding catheter was positioned in the ostium of the left coronary artery using Judkins' technique. Nonionic contrast medium (Omnipaque, Nycomed, Oslo, Norway) was used to avoid a myocardial depressant effect during coronary angiography. Hemodynamic measurements were performed without contrast medium.

Balloon inflation was performed 3-5 times for each patient with a standard coronary angioplasty balloon catheter. Each inflation was performed for $60 \mathrm{~s}$ after an interval of $1 \mathrm{~min}$ for hemodynamic recovery. The mean balloon inflation pressure was $8 \pm 2$ atmosphere. The mean balloon size was $3.1 \pm 0.5 \mathrm{~mm}$. Dilatation was considered successful if the residual stenosis was assessed as less than $50 \%$ by quantitative coronary angiography. After the coronary stenosis was dilated by the PTCA procedure, the RW study was performed.
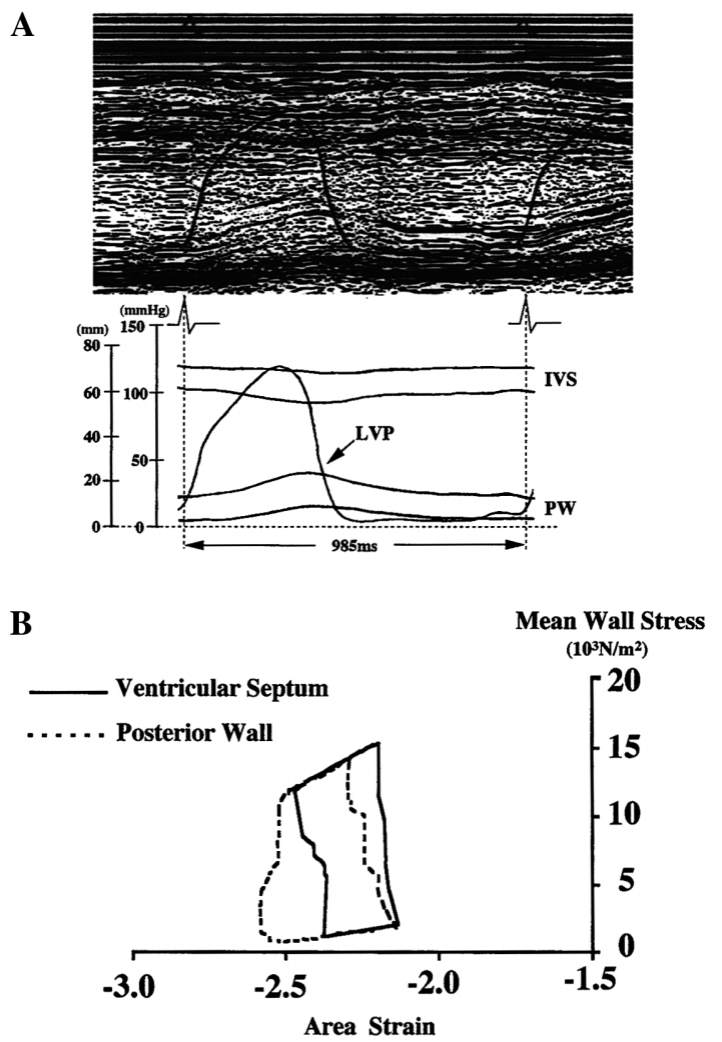

Fig 1. (A) Simultaneous recording of LV pressure (LVP) and Mmode echocardiogram of a normal subject (Top). Cardiac cycle tracings of LVP and epi- and endocardial surfaces of the interventricular septum (IVS) and posterior wall (PW) of the LV (Bottom). (B) The mean wall stress - natural logarithm of the reciprocal of wall thickness $[\sigma-\ln (1 / \mathrm{H})]$ loops obtained from a normal subject. The dotted line indicates the loop for the PW of the $\mathrm{LV}$ and the solid line is the loop for the IVS. The area enclosed by a $\epsilon-\ln (1 / \mathrm{H})$ loop during a cardiac cycle gives the regional work per unit volume of myocardium. The mean wall stress $(\sigma)$ was defined as $\mathrm{DP} / 4 \mathrm{H}$, and the strain $(\epsilon)$ was defined as $\ln (1 / \mathrm{H})$.

\section{Regional Work of the Left Ventricle}

A 6F micromanometer-tipped catheter (Millar SPC-464 D; Houston, TX, USA) was inserted into the LV through the femoral artery to measure pressure, and then echocardiography was performed using a phased-array scanner (Hewlett Packard, Boston, MA USA) with a $2.5 \mathrm{MHz}$ transducer. The transducer was placed at the third or fourth intercostal space at the left sternal border, and the shortaxis view of the LV just above the mid-papillary muscle was obtained. The M-mode cursor was positioned centrally on the 2-D image of the short-axis cross-section of the LV, and the derived M-mode image was recorded. LV pressure (LVP) was also recorded, simultaneously, on the M-mode echocardiogram at a paper speed of $100 \mathrm{~mm} / \mathrm{s}$ (Fig 1A). The data were collected every $10 \mathrm{~s}$. LVP and the epi- and endocardial surfaces were traced carefully with a handcontrolled cursor.

The tracings were scanned and fed into a computer system (Apple Power Macintosh 8100/80; Cupertino, CA, USA), and LVP, LV short-axis internal diameter, and the thickness $(\mathrm{H})$ of the ventricular septum and the posterior wall (PW) were digitized over one cardiac cycle. The data were sampled at 40 points during one cardiac cycle. The stress $(\sigma)$-strain $(\epsilon)$ relations for the ventricular septum 
Blood Pressure

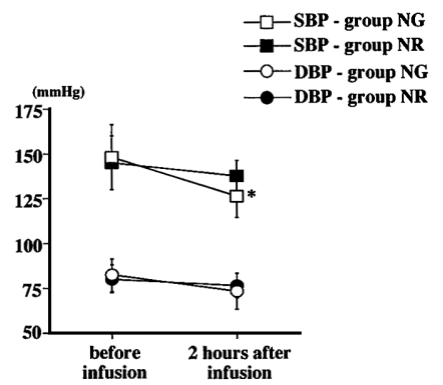

Heart Rate

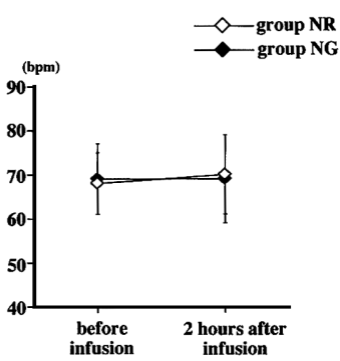

Fig 2. Changes in blood pressure and heart rate after infusion of nicorandil and nitroglycerin. ${ }^{*} \mathrm{p}<0.05$ vs before infusion. SBP, systolic blood pressure; DBP, diastolic blood pressure.

and the PW were delineated (Fig 1B). The area surrounded by the $\sigma-\epsilon$ loop during a cardiac cycle is equal to regional work per unit volume of myocardium. If the loop rotates counterclockwise, the region performs positive work. If the loop rotates clockwise, the region performs negative work; that is, the work is done on the region by the surrounding myocardium.

For simplicity, we used a spherical model of the LV to calculate mean wall stress. The stress was defined as $\mathrm{PD} / 4 \mathrm{H}$, and the strain was defined as $\ln 1 / \mathrm{H}$ (the natural logarithm of the reciprocal of wall thickness).

\section{Statistical Analysis}

We tested sequential changes in LV diameter, LVP and RW during balloon inflation by repeated measures analysis of variance (ANOVA). Comparisons of mean changes in groups NR and NG were performed using two-way ANOVA and the post hoc test. All other data were compared using Student's t-test. A probability value of less than 0.05 was considered significant. All data were expressed as mean \pm SD.

\section{Results}

No complications related to the coronary angioplasty procedure were noted in any of the patients. After PTCA, the mean residual stenosis was $18 \pm 8 \%$ in group NR and $16 \pm 10 \%$ in group NG. The frequency of balloon inflation before the study was $4.0 \pm 0.9$ times in group NR and $4.4 \pm 0.7$ times in group NG. There was no significant difference between the 2 groups.

\section{ECG Study}

ST-segment elevation was $0.07 \pm 0.07 \mathrm{mV}$ in group NR and $0.11 \pm 0.10 \mathrm{mV}$ in group NG. Statistically significant differences between group NR and group NG were not found.

\section{Blood Pressure and Heart Rate After Intravenous Infusion of Nicorandil or Nitroglycerin (Fig 2)}

The baseline systolic blood pressure was $145 \pm 15 \mathrm{mmHg}$ in group NR and $148 \pm 18 \mathrm{mmHg}$ in group NG. At $2 \mathrm{~h}$ after intravenous infusion of NR $\left(1.5 \mu \mathrm{g} \cdot \mathrm{kg}^{-1} \cdot \mathrm{min}^{-1}\right)$ or NG $\left(0.5 \mu \mathrm{g} \cdot \mathrm{kg}^{-1} \cdot \mathrm{min}^{-1}\right)$, blood pressure was $137 \pm 9 \mathrm{mmHg}$ and $126 \pm 12 \mathrm{mmHg}$, respectively. Systolic blood pressure was significantly decreased from the baseline $(\mathrm{p}<0.05)$ in group $\mathrm{NG}$, but in group NR, it was not significantly changed. No statistically significant changes in diastolic blood pressure


Fig 3. Changes in LV dimensions and pressure. (A) LV end-diastolic dimension (LVDd) and end-systolic dimension (LVDs) were significantly increased soon after balloon inflation. Following balloon deflation, the dimensions decreased and returned to the baseline values. (B) LV end-systolic pressure (ESP) decreased and end-diastolic pressure (EDP) increased after balloon inflation, then returned to the baseline level. ${ }^{*} \mathrm{p}<0.05$ vs pre-inflation, ${ }^{*} \mathrm{p}<0.05$ vs group NG.

or heart rate were found in either group.

\section{Dimension (Fig 3A)}

The baseline LV end-diastolic dimension (LVDd) was $47 \pm 4 \mathrm{~mm}$ in group NR and $48 \pm 4 \mathrm{~mm}$ in group NG. The LVDd significantly increased within $40 \mathrm{~s}$ after balloon inflation $(\mathrm{p}<0.05)$, and was $50 \pm 4 \mathrm{~mm}$ in group NR and $54 \pm 4 \mathrm{~mm}$ in group $\mathrm{NG}$ at the end of balloon inflation. Following balloon deflation, the LVDd decreased and recovered its baseline value at approximately $30 \mathrm{~s}$ after deflation. No statistically significant differences were found between the 2 groups.

The baseline LV end-systolic dimension (LVDs) was $28 \pm 3 \mathrm{~mm}$ in group NR and $28 \pm 3 \mathrm{~mm}$ in group NG. The LVDs increased immediately after balloon inflation, and was $40 \pm 4 \mathrm{~mm}$ in group NR and $42 \pm 4 \mathrm{~mm}$ in group NG at the end of balloon inflation. Following balloon deflation, the LVDs decreased and recovered its baseline value at approximately $30 \mathrm{~s}$ after deflation. No statistically significant differences were found between the 2 groups.

\section{Pressure (Fig 3B)}

The baseline LV end-diastolic pressure was $12 \pm 3 \mathrm{mmHg}$ in group NR and $12 \pm 3 \mathrm{mmHg}$ in group NG. End-diastolic pressure increased within 30-40 s of balloon inflation, and rose to $17 \pm 3 \mathrm{mmHg}$ in group $\mathrm{NR}$ and $19 \pm 4 \mathrm{mmHg}$ in group $\mathrm{NG}$ at the end of balloon inflation. Following balloon deflation, the end-diastolic pressure decreased gradually and reached its baseline value at $40 \mathrm{~s}$ after deflation in group $\mathrm{NG}$, but at $20 \mathrm{~s}$ after deflation in group NR.

The baseline LV end-systolic pressure was $136 \pm 7 \mathrm{mmHg}$ in group NR and $128 \pm 10 \mathrm{mmHg}$ in group NG. End-systolic pressure decreased within 20-30 s after balloon inflation, and was $122 \pm 7 \mathrm{mmHg}$ in group NR and $111 \pm 10 \mathrm{mmHg}$ in 
A

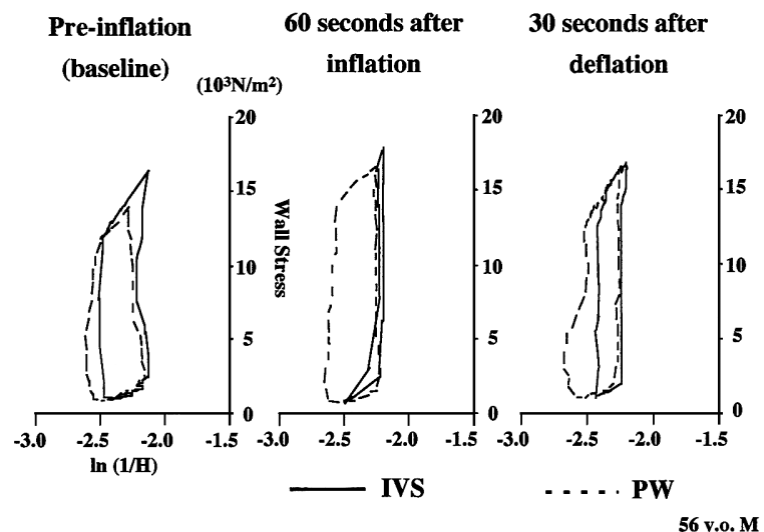

B



Fig 4. Changes in the stress $(\sigma)$-strain $(\epsilon)$ loops during PTCA in one patient each from group NG (A) and group NR (B). (Left) Before balloon inflation, (Middle) at $60 \mathrm{~s}$ after balloon inflation, (Right) $30 \mathrm{~s}$ after balloon deflation. (A) The $\sigma-\epsilon$ loop of the interventricular septum became extremely narrow and shifted to the right, whereas that of the LV posterior wall became a little broader at $60 \mathrm{~s}$ after inflation. The loop of the interventricular septum went back to baseline at $30 \mathrm{~s}$ after balloon deflation. (B) Changes in the $\sigma-\epsilon$ loops were smaller in group NR than in group NG.

group NG at the end of balloon inflation. Following balloon deflation, end-systolic pressure increased and returned to baseline at $40 \mathrm{~s}$ after deflation. From 10 to $20 \mathrm{~s}$ after balloon deflation, the end-systolic pressure in group NR was significantly higher than that in group NG $(\mathrm{p}<0.05)$.

\section{Stress ( $\sigma)$ - Strain $(\epsilon)$ Relation}

Fig 4A shows the $\sigma-\epsilon$ loops from a patient in group NG. The $\sigma-\epsilon$ loop of the interventricular septum (IVS) became extremely narrow, and the area surrounded by the $\sigma-\epsilon$ loop of the LV PW became larger at $60 \mathrm{~s}$ after balloon inflation. The loop of the IVS recovered to the baseline at $30 \mathrm{~s}$ after balloon deflation.

Fig 4B shows the data from a patient in group NR. The $\sigma-\epsilon$ loop of the IVS became narrower compared with the baseline, although the loop of the LV PW remained almost unchanged at $60 \mathrm{~s}$ after balloon inflation. The $\sigma-\epsilon$ loop of the IVS recovered to baseline at $30 \mathrm{~s}$ after deflation. Changes in the $\sigma-\epsilon$ loops were smaller in group NR than in group NG.

\section{Left Ventricular Regional Work (Fig 5)}

The baseline RW of the IVS was $5.7 \pm 1.0 \mathrm{~mJ} / \mathrm{cm}^{3}$ in group $\mathrm{NR}$ and $5.4 \pm 0.9 \mathrm{~mJ} / \mathrm{cm}^{3}$ in group NG. It decreased immediately after balloon inflation and fell to $1.2 \pm 0.7 \mathrm{~mJ} / \mathrm{cm}^{3}$

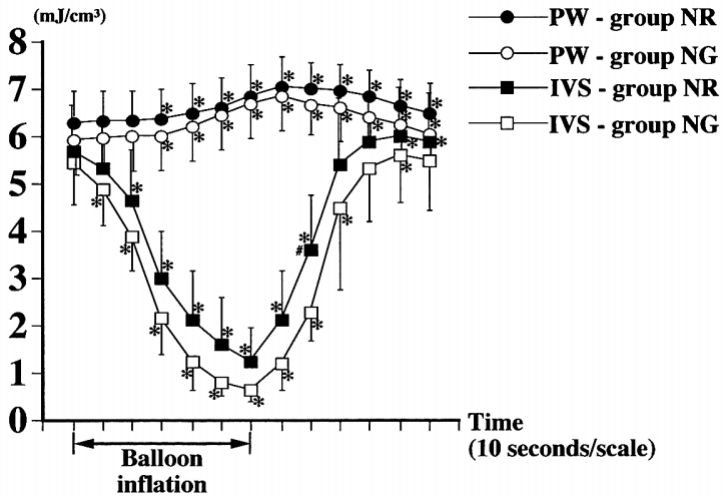

Fig 5. Changes in LV regional work. Regional work of the interventricular septum (IVS) decreased immediately after balloon inflation. After balloon deflation, the regional work increased, and returned to baseline at $30 \mathrm{~s}$ after deflation in group NR and at $40 \mathrm{~s}$ in group NG. Regional work of the posterior wall (PW) increased after balloon inflation and reached its maximal value at $10 \mathrm{~s}$ after deflation. Subsequently, the regional work decreased, but did not recover to baseline even at $60 \mathrm{~s}$ after deflation in both groups. ${ }^{*} \mathrm{p}<0.05$ vs preinflation, ${ }^{\#} \mathrm{p}<0.05$ vs group NG.

in group NR and $0.6 \pm 0.3 \mathrm{~mJ} / \mathrm{cm}^{3}$ in group $\mathrm{NG}$ at the end of balloon inflation. After balloon deflation, the IVS RW increased, and recovered its baseline value at $30 \mathrm{~s}$ after deflation in group NR and at $40 \mathrm{~s}$ after deflation in group NG. At $20 \mathrm{~s}$ after balloon deflation, the IVS RW in group NR $\left(3.6 \pm 1.2 \mathrm{~mJ} / \mathrm{cm}^{3}\right)$ was significantly higher than that in group NG $\left(2.3 \pm 0.6 \mathrm{~mJ} / \mathrm{cm}^{3}\right)(\mathrm{p}<0.05)$. At $50 \mathrm{~s}$ after deflation, it was significantly higher than the baseline value in both groups (group $\mathrm{NR}, 6.0 \pm 1.0 \mathrm{~mJ} / \mathrm{cm}^{3}$; group $\mathrm{NG}$, $\left.5.6 \pm 1.0 \mathrm{~mJ} / \mathrm{cm}^{3}, \mathrm{p}<0.05\right)$.

Baseline RW of the PW was $6.3 \pm 0.7 \mathrm{~mJ} / \mathrm{cm}^{3}$ in group $\mathrm{NR}$ and $5.9 \pm 0.7 \mathrm{~mJ} / \mathrm{cm}^{3}$ in group NG. The RW of the PW increased within $40 \mathrm{~s}$ after balloon inflation and reached $7.0 \pm 0.6 \mathrm{~mJ} / \mathrm{cm}^{3}$ in group NR and $6.8 \pm 0.7 \mathrm{~mJ} / \mathrm{cm}^{3}$ in group NG at $10 \mathrm{~s}$ after balloon deflation. Subsequently, it decreased, but did not recover within $60 \mathrm{~s}$ after deflation in either group.

\section{Discussion}

\section{Determination of the Doses of Nicorandil and Nitroglycerin}

The recommended dose of NR for patients with unstable angina pectoris in Japan is $4-6 \mathrm{mg} / \mathrm{h}$, and when taking the Japanese constitution into consideration, the appropriate dose is considered to be approximately $1.5 \mu \mathrm{g} \cdot \mathrm{kg}^{-1} \cdot \mathrm{min}^{-1}$, which is the dose we used in the present study. Tsutamoto et al have reported on the hemodynamic changes after intravenous infusion of either NR or NG in patients with heart failure ${ }^{24}$ The dose necessary to achieve more than $20 \%$ reduction of pulmonary capillary wedge pressure within $1 \mathrm{~h}$ was $1.0-6.0 \mu \mathrm{g} \cdot \mathrm{kg}^{-1} \cdot \mathrm{min}^{-1}$ of $\mathrm{NR}$ and $0.25-$ $1.5 \mu \mathrm{g} \cdot \mathrm{kg}^{-1} \cdot \mathrm{min}^{-1}$ of NG; that is, the dose of NR was 3- to 4-fold higher than that of NG. Furthermore, that report indicated that there were no statistically significant changes in heart rate, mean blood pressure, cardiac index or systemic vascular resistance with these doses. Therefore, we decided to administer $0.5 \mu \mathrm{g} \cdot \mathrm{kg}^{-1} \cdot \mathrm{min}^{-1}$ of $\mathrm{NG}$, equivalent to one-third of the dose of NR. 


\section{Effect of Nicorandil on Blood Pressure and Heart Rate}

Our study results suggest that continuous intravenous infusion of NR in patients with angina pectoris during PTCA, which titrated at a dose of $1.5 \mu \mathrm{g} \cdot \mathrm{kg}^{-1} \cdot \mathrm{min}^{-1}$, had no influence on blood pressure or heart rate. Tsutamoto et $\mathrm{al}^{24}$ and Larsen et al 25 also reported no significant changes in blood pressure before and after infusion of NR, even when the dose was larger than that used in the present study. Therefore, NR can be used safely in patients with low blood pressure.

\section{Effect of Nicorandil on Myocardial Ischemia and Regional Work}

The degree of electrophysiological myocardial ischemia was similar between groups NR and NG, as statistically significant differences in the electrocardiographic maximum ST-segment elevation between the 2 groups were not found. Also, the depression in RW caused by balloon inflation was similar between the 2 groups. However, NR led to a better recovery of the RWwork from ischemia compared with NG. In isolated-perfused rat hearts, NR improved the functional and metabolic recovery after global ischemia and reperfusion, ${ }^{26-29}$ suggesting that NR has a direct cardioprotective action and potential clinical usefulness as an adjunct therapy during reperfusion after angioplasty or thrombolysis, enabling PTCA to be performed with more safety. Because NR is not considered to develop tolerance $^{24,25}$ and has an anti-arrhythmic effect unlike nitrates because of electrocardiographic QT interval shortening, ${ }^{30-32}$ it is considered to be very useful to the patients with ischemic heart disease.

\section{Can the Present Dose of Nicorandil Open the Potassium Channel?}

Little is known about which dose of NR is suitable for inducing the potassium channel opening effect. In the previous studies of continuous intravenous infusion of NR, the dose was larger than that used in our study. In addition, few attempts have been made at continuous intravenous infusion of NR in human. However, because RW in group NR showed a better recovery from ischemia than group $\mathrm{NG}$, it is reasonable to consider that $1.5 \mu \mathrm{g} \cdot \mathrm{kg}^{-1} \cdot \mathrm{min}^{-1}$ of NR has a potassium channel opening effect, even if the hemodynamics were not significantly changed.

\section{Regional Work}

In each patient, the reduction in LV RW induced by myocardial ischemia occurred earlier and was more remarkable than the changes in ECG, LV dimension and LVP, which suggests that LV RW may be the most sensitive index of myocardial ischemia.

\section{Clinical Implications}

The cardioprotective effects of NR have been confirmed in several clinical studies of patients with ischemic heart diseases, but the majority of those patients had acute myocardial infarction and the studies were concerned with stunned myocardium. The present study is the first to evaluate the beneficial effects of NR administrated at a clinically appropriate dose during standard PTCA in which inflation was performed for $60 \mathrm{~s}$. In most previous studies, NR was administered as an intravenous bolus or an intracoronary injection, both of which may have an unstable blood concentration and less influence on hemodynamics and cardiac status rather than a continuous intravenous infusion. In addition, the dose of NR was not related to the patient's body weight and was often greater than the clinical dose. Few studies have evaluated myocardial function during acute brief ischemia, such as during coronary angioplasty. In the present study, the dose of NR was the same as that used clinically for continuous intravenous infusion, and the better effects of NR were proven in routine angioplasty by quantitative evaluation of the changes in RW. Because no significant changes occurred in blood pressure before and after infusion of NR, we consider that it can be used safely in patients with angina pectoris, especially those with hypotension.

\section{Study Limitations}

Comparison of Nicorandil and Nitroglycerin We did not compare the effects of NR and NG in the same subject. However, there were no significant differences in age, gender or other clinical findings between the 2 groups. There are no other studies that have compared the effects of NR and NG during and after a brief acute myocardial ischemia in the same subjects or in the same animal.

Difference in Collateral Circulation During Balloon Inflation In other studies, we have encountered subjects who had good collateral circulation from the right coronary artery to the LAD when we performed contralateral angiography during PTCA to the LAD, although the collateral circulation was not observed before the intervention. ${ }^{21}$ In the present study, however, we did not evaluate collateral circulation during balloon inflation to the LAD. There may have been some prior differences in collateral circulation between the 2 groups according to the degree of prodromal myocardial ischemia. However, all the study subjects were patients with stable angina pectoris and the frequency of chest pain was less than twice per week, so we considered that there was not any significant difference in the degree of collateral circulation during inflation between the groups NR and NG.

Discrepancy of the Sampling Point in Echocardiography The heart deviates not only toward the short axis but also toward the long axis, accompanied by twists in the systole-diastole phase. If the transducer is fixed at the thorax, the sampling point has a slight discrepancy accompanied a cardiac cycle, which can affect the result of the RW study.

Accuracy of the Regional Work Method The accuracy of the method used to calculate RW is limited by the accuracy in determining the mean wall stress, as discussed in detail in the original reports on this method!2,17 When regional ischemia develops, local deformities may occur in the affected area and the assumption that the whole ventricle is spherical may include a certain amount of error. Theoretically, it is possible to improve the accuracy of the method by assuming a region of the ventricular wall to be locally spherical. The method can be applied to that region locally without any modification. However, it is then necessary to measure the radius of local curvature of the ventricular wall and currently there is no known method of doing that and we did not attempt it. We must stress that this is the only method that gives not only relative changes in RW, but also the absolute value in the true dimension of work (ie, $\mathrm{mJ} / \mathrm{cm}^{3}$ ).

\section{Conclusions}

Intravenous infusion of NR at a clinically appropriate 
dose led to good recovery of RW from ischemia, compared with that obtained with NG, without a significant effect on blood pressure.

\section{References}

1. Samaha FF, Heineman FW, Ince C, Fleming J, Balsaban RS. ATPsensitive potassium channel is essential to maintain basal coronary vascular tone in vivo. Am J Physiol 1992; 262: C1220-C1227.

2. Suryapranata H, MacLeod D. Nicorandil and cardiovascular performance in patients with coronary artery disease. $J$ Cardiovasc Pharmacol 1992; 20(Suppl 3): 45-51.

3. Edwards G, Weston AH. Potassium channel openers and vascular smooth muscle relaxation. Pharmacol Ther 1990; 48: 237-258.

4. Thormann J, Schlepper M, Kramer W, Gottwik M, Kindler M. Effectiveness of nicorandil (SG-75), a new long-acting drug with nitroglycerin effects in patients with coronary artery disease: Improved left ventricular function and regional wall motion and abolition $\mathrm{pf}$ pacing-induced angina. J Cardiovasc Pharmacol 1983; 3: 371 - 377 .

5. Holzmann S. Cyclic GMP as possible mediator of coronary arterial relaxation by nicorandil (SG-75). J Cardiovasc Pharmacol 1983; 3: 364-370.

6. Brown BG. Response of normal and diseased epicardial coronary arteries to vasoactive drugs: Quantitative angiographic studies. Am J Cardiol 1985; 56: 23E-29E.

7. Igunarro LJ, Lippton H, Edwards JC. Mechanism of vascular smooth muscle relaxation by organic nitrates, nitrites, nitroprusside and nitric oxide: Evidence for the involvement of S-nitrosothiols as active intermediates. J Pharmacol Exp Ther 1981; 3: 739-749.

8. Parker JO, Oates JA, Wood AJJ. Nitrate therapy in stable angina pectoris. N Engl J Med 1987; 26: 1635-1642.

9. Murad F. Cyclic guanosine monophosphate as a mediator of vasodilation. J Clin Invest 1986; 78: 1-5.

10. Auchampach JA, Cavero I, Gross GJ. Nicorandil attenuates myocardial dysfunction associated with transient ischemia by opening ATPdependent potassium channels. J Cardiovasc Pharmacol 1992; 20: $765-771$.

11. Sugawara M, Nakano K, Kawana M, Umemura J, Sasayama S, Carabello BA. Regional work of the left ventricle and contractility index independent of ventricular size. In: Sasayama $\mathrm{S}$, Suga $\mathrm{H}$, editors. Recent progress in failing heart syndrome. Tokyo: SpringerVerlag; 1991: 257-279.

12. Nakano K, Sugawara M, Kato T, Sasayama S, Carabello BA, Asanoi $\mathrm{H}$, et al. Regional work of the human left ventricle calculated by wall stress and the natural logarithm of reciprocal of wall thickness. $J \mathrm{Am}$ Coll Cardiol 1988; 12: $1442-1448$

13. Sugawara M, Tamiya K, Nakano K. Regional work of the ventricle: Wall tension-area relation. Heart Vessels 1985; 1: 133-144.

14. Nakano K, Sugawara M, Tamiya K, Satomi G, Koyanagi H. A new approach to defining regional work of the ventricle and evaluating regional cardiac function: Mean wall stress-natural logarithm of reciprocal of wall thickness relationship. Heart Vessels 1986; 2: 74-80.

15. Sugawara M, Nakano K. A method of analyzing regional myocardial function: Mean wall stress-area strain relationship. Jpn Circ J 1987; 51: $120-124$.

16. Sugawara M, Nakano K. A method of analyzing regional myocardial function of the ventricle. In: Hori M, Suga H, Baan J, Yellin EL, editors. Cardiac mechanics and function in the normal and diseased heart. Tokyo: Springer-Verlag; 1989: 249-256.
17. Nakano K, Sugawara M, Ishihara K, Kanazawa S, Corin WJ, Denslow S, et al. Myocardial stiffness derived from end-systolic wall stress and logarithm of reciprocal of wall thickness: Contractility index independent of ventricular size. Circulation 1990; 82: $1352-$ 1361

18. Yanagida R, Sugawara M, Kawai A, Koyanagi H. Regional differences in myocardial work of the left ventricle in patients with idiopathic dilated cardiomyopathy: Implication for the surgical technique used for left ventriculoplasty. J Thorac Cardiovasc Surg 2001; 122: $600-707$.

19. Goto Y, Igarashi Y, Yasumura Y, Nozawa T, Futaki S, Hiramori K, et al. Integrated regional work equals total left ventricular work in regionally ischemic canine heart. Am J Physiol 1988; 254: H894H904.

20. Nakano K, Nakatani H, Endo M, Magosaki N, Tamura K, Sugawara $\mathrm{M}$, et al. Regional work of the left ventricle before and after CABG. J Jpn Assn Thorac Surg 1995; 43: 14-18.

21. Higashita R, Sugawara M, Kondo Y, Kawai Y, Mitsui K, Oki S, et al. Changes in diastolic regional stiffness of the left ventricle before and after coronary artery bypass grafting. Heart Vessels 1996; 11: $145-151$.

22. Isobe $\mathrm{N}$, Oshima $\mathrm{S}$, Taniguchi $\mathrm{K}$, Hoshizaki $\mathrm{H}$, Adachi $\mathrm{H}$, Toyama $\mathrm{T}$, et al. Electrocardiographic ST-segment elevation and changes in the regional work of the left ventricle during coronary angioplasty. Jpn Circ J 2001; 65: 150-154.

23. Isobe $\mathrm{N}$, Oshima $\mathrm{S}$, Taniguchi $\mathrm{K}$, Hoshizaki $\mathrm{H}$, Adachi $\mathrm{H}$, Toyama $\mathrm{T}$, et al. Does repeated balloon inflation during coronary angioplasty induce ischemic tolerance? Analysis based on regional work. Heart Vessels 2000; 15: 117-123.

24. Tsutamoto T, Kinoshita M, Nakae I, Maeda Y, Wada A, Yabe T, et al. Absence of hemodynamic tolerance to nicorandil in patients with severe congestive heart failure. Am Heart J 1994; 127: 866-873.

25. Larsen AI, Goransson L, Aarsland T, Tamby JF, Dickstein K. Comparison of the degree of hemodynamic tolerance during intravenous infusion of nitroglycerin versus nicorandil in patients with congestive heart failure. Am Heart J 1997; 134: 435-441.

26. Grover GJ, Sleph PG, Perham CS. Nicorandil improves postischemic contractile function independently of direct myocardial effects. $J$ Cardiovasc Pharmacol 1990a; 15: 698-905.

27. Pieper GM, Gross GJ. Protective effect of nicorandil on postischemic function and tissue adenosine nucleotides following a brief period of low-flow global ischemia in the isolated perfused rat heart. Pharmacology 1989; 38: 205-213.

28. Ohta H, Jinno Y, Harada K, Ogawa N, Fukushima H, Nishikori K. Cardioprotective effects of KRN2391 and nicorandil on ischemic dysfunction in perfused rat heart. Eur J Pharmacol 1991; 204: 171177.

29. Mitani A, Kinoshita K, Fukamachi K. Effects of glibenclamide and nicorandil on cardiac function during ischemia and reperfusion in isolated perfused rat hearts. Am J Physiol 1991; 261: H1864H1871.

30. Imanishi S, Arita M, Aomine M, Kiyosue T. Antiarrhythmic effects of nicorandil on canine Purkinje fibers. J Cardiovasc Pharmacol 1984; 6: 772-779.

31. Lathrop DA, Nanasi PP, Varro A. In vitro cardiac models of dog Purkinje fiber triggered and spontaneous electrical activity: Effects of nicorandil. Br J Pharmacol 1990; 99: 119-123.

32. Takahashi N, Ito M, Saikawa T, Arita M. Nicorandil suppresses early after depolarization and ventricular arrhythmias induced by calcium chloride in rabbits in vivo. Cardiovasc Res 1991; 25: 445-452. 